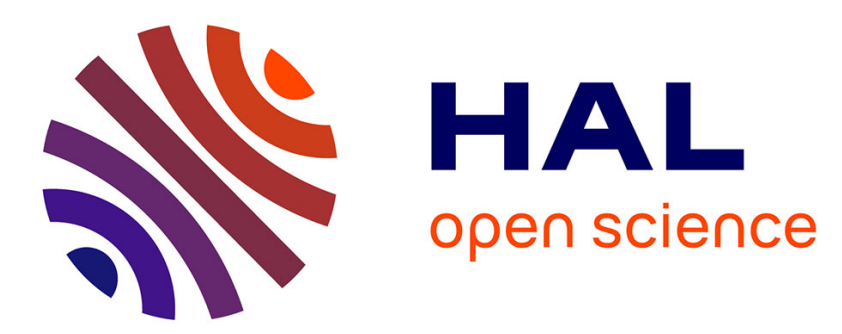

\title{
Highlighting metabolic indicators of olive oil during storage by the AComDim method
}

R Korifi, J. Plard, Y Le Dréau, C. Rébufa, Douglas Rutledge, Nathalie Dupuy

\section{To cite this version:}

R Korifi, J. Plard, Y Le Dréau, C. Rébufa, Douglas Rutledge, et al.. Highlighting metabolic indicators of olive oil during storage by the AComDim method. Food Chemistry, 2016, 203, pp.104-116. 10.1016/j.foodchem.2016.01.137 . hal-01450841

\section{HAL Id: hal-01450841 \\ https://hal.science/hal-01450841}

Submitted on 13 Apr 2018

HAL is a multi-disciplinary open access archive for the deposit and dissemination of scientific research documents, whether they are published or not. The documents may come from teaching and research institutions in France or abroad, or from public or private research centers.
L'archive ouverte pluridisciplinaire HAL, est destinée au dépôt et à la diffusion de documents scientifiques de niveau recherche, publiés ou non, émanant des établissements d'enseignement et de recherche français ou étrangers, des laboratoires publics ou privés. 


\title{
Highlighting metabolic indicators of olive oil during storage by the AComDim method
}

\author{
R. Korifi ${ }^{a}$, J. Plard ${ }^{a}$, Y. Le Dréau ${ }^{a}$, C. Rébufa ${ }^{a}$, D.N. Rutledge ${ }^{b}$, N. Dupuy ${ }^{a}$ \\ ${ }^{a}$ Aix-Marseille Université, LISA EA4672, 13397 Marseille, France \\ b UMR Ingénierie Procédés Aliments, AgroParisTech, INRA, Université Paris-Saclay, 91300 Massy, France
}

\begin{abstract}
A B S T R A C T
Lipid oxidation during olive oil storage induces changes in the metabolite content of the oil, which can be measured using so-called quality indices. High values indicate poor quality oils that should be labeled accordingly or removed from the market. Based on quality indices measured over two years for two olive oils, the AComDim method was used to highlight the influence of five factors (olive oil type, oxygen, light, temperature and storage time) on oxidative stability during storage. To identify the significant factors, two full factorial experimental designs were built, each containing four of the five factors examined. The results showed that all five factors, as well as some two-factor interactions, were significant. Phenols and hydroperoxides were identified as being the most sensitive to these factors, and potential
\end{abstract}

Keywords:

Experimental design

Multivariate

Metabolite

Olive oil ageing

Quality indices

\section{Introduction}

Outside of the inherent agronomic factors, good sensory characteristics of olive oil are already protected by controls during growth, processing and storage where oxidation of lipids might occur. To estimate the chemical quality of oil, the International Olive Council (IOC), European regulation, and the International Organization for Standardisation (ISO) recommend measuring quality indices for profiling metabolites present. The major classes of metabolites tracked are fatty acids (saturated fatty acids, mono unsaturated fatty acids and poly unsaturated fatty acids) (Casal, Malheiro, Sendas, Oliveira, \& Pereira, 2010). Peroxide value (PV) is used to evaluate primary metabolites, such as hydroperoxides and peroxides, which are susceptible to oxidation and form secondary metabolites, including aldehydes or free fatty acids, detected by the p-anisidine value (AV) (Shahidi \& Zhong, 2005) and the free acidity (FA), respectively. Some authors (Poulli, Mousdis, \& Georgiou, 2009) believe the total oxidation value $($ TOTOX $=2 \mathrm{PV}+\mathrm{AV}$ ) gives a better estimation of deterioration. Total phenols content is the most common method used to determine the antioxidant potential of olive oil. The spectroscopic indices, $\mathrm{K}_{232}$ and $\mathrm{K}_{270}$, are used to characterize conjugated dienes

E-mail addresses: rabia.korifi@yahoo.fr (R. Korifi), plard.jerome@live.fr (J. Plard), yveline.le-dreau@univ-amu.fr (Y. Le Dréau), c.rebufa@univ-amu.fr (C. Rébufa), rutledge@agroparistech.fr (D.N. Rutledge), nathalie.dupuy@univ-amu.fr (N. Dupuy). and trienes, respectively, formed from hydroperoxides of polyunsaturated fatty acids and their oxidation products (Pristouri, Badeka, \& Kontominas, 2010).

To maintain the organoleptic and nutritional properties of newly produced olive oil, it is important to protect it from oxygen, light and heat during storage and commercialization (Bendini, Cerretani, Salvador, Fregapane, \& Lercker, 2010). Several studies have reported that changes in metabolite profiles are due to the oxygen concentration in oil, as a result of processing and storage as well as of the oxygen permeability of the packaging material. Mendez and Falqué (2007) concluded from measures of quality indices (PV, FA, $\mathrm{K}_{232}, \mathrm{~K}_{270}$, total phenols and fatty acids composition at 0,3 and 6 months of oil storage) that transparent plastic packaging is not ideal, and that tin-coated steel or plasticpaperboard-steel preserved the oil best. Pristouri et al. (2010) studied the headspace air quantity effect in plastic containers stored in darkness at $22^{\circ} \mathrm{C}$. They conclude that olive oil should be stored in opaque glass bottles at $22{ }^{\circ} \mathrm{C}$ and, once opened, the remaining oil should be transferred to a smaller container to limit the presence of oxygen in the headspace. Di Giovacchino et al. (2002) showed that the oil quality is preserved for longer when an inert gas, such as nitrogen, is used for conditioning the bottles. Several authors (Gomez-Alonso, Mancebo-Campos, Desamparados Salvador, \& Fregapane, 2007; Kiritsakis \& Dugan, 1985; Morelló, Motilva, Tovar, \& Romero, 2004; Psomiadou \& Tsimidou, 1998) have shown that the oxidation proceeds more slowly in the dark, more rapidly 
in diffuse light and most rapidly in direct sunlight. When the exposure time is relatively short ( 3 months), the impact of light on PV and $\mathrm{K}_{232}$ is difficult to quantify, but between 12 and 21 months, $\mathrm{PV}, \mathrm{K}_{232}$ and $\mathrm{K}_{270}$ increase linearly until they exceed acceptable limits ( 20 meq $\mathrm{O}_{2} \mathrm{~kg}^{-1}, 2.5$ and 0.25 , respectively). Few modifications have been recorded for the composition of unsaturated fatty acids, but some changes have been observed in the composition of the polyunsaturated acids. Heat also influences many of the complex reactions involved in lipid oxidation and increases the formation of primary and secondary metabolites. Thus, quality indices increase faster with storage at high temperatures. Olive oil degradation depends heavily on the initial phenols content.

Recent publications have shown that the determination of numerous physicochemical parameters, combined with classification methods, has potential for monitoring the oxidation of edible oils and to differentiate amongst them, based on the cultivar and geographic origin (Karabagias et al., 2013; Sousa et al., 2015) or their oxidative status (Bouchaala, Lazzez, Jabeur, Daoud, \& Bouaziz, 2014; Bucci, Magrí, Magrí, Marini, \& Federico Marini, 2002).

The samples used in this study were commercially available olive oils greatly appreciated by consumers, even though they had defects, according to European standards. They were derived from the same Aglandau variety, but came from olives collected at two different maturity stages. Ageing was carried out under different storage conditions to determine the impact of extrinsic factors, such as oxygen, light and temperature $\left(4{ }^{\circ} \mathrm{C}, 21^{\circ} \mathrm{C}\right.$ and $18-$ $30^{\circ} \mathrm{C}$ ) as well as storage time. The metabolic changes were tracked every four months over two years by measuring quality indices (PV, AV, TOTOX, FA, total phenols contents, $\mathrm{K}_{232}, \mathrm{~K}_{270}$ and fatty acids content). These experimental data were used as responses of two full factorial experimental designs, each built on a combination of four of the five factors (oil type, oxygen, light, temperature and storage time) so that the design is balanced. The influence of the different experimental factors, as well as their interactions, were simultaneously analysed using a multivariate analysis technique, the AComDim method (Bouveresse, Pinto, Schmidtke, Locquet, \& Rutledge, 2011). This novel method for the detection of significant factors has been applied to spectral datasets from a variety of samples, e.g., wine, to study the influence of the vintage (year), maceration method and/or micro-oxygenation; apple, to study the influence of the cultivar and the maturity; starch-lignin mixtures, to study humidity, shape and lignin content (Bouveresse et al., 2011). This method has also been used to study the effects of experimental factors on the quality of spectral responses for commercial diesel (Amat, Dupuy, Kister, \& Rutledge, 2010). In contrast to the ANOVA-PCA method (Harrington et al., 2005), AComDim replaces successfully the separate PCAs with a single analysis to give an evaluation of significance of the effects (Pinto, Bosc, Noçairi, Barros, \& Rutledge, 2008).

The aim of the work presented in this article was to determine the significant factors influencing oil quality as well as any interaction, based on the AComDim salience factors graph. This approach also highlights the significant quality indices to describe the oxidative state of olive oils. Thus, it is possible to know which metabolites (peroxides, aldehydes, free acids, phenols, conjugated dienes or trienes, fatty acids) are best retained as markers of ageing.

\section{Material and methods}

\subsection{Olive oil samples}

Two commercial olive oils, one of the "green fruity" type and the other of the "black fruity" type, were obtained from the same Aglandau cultivar, which is most widespread cultivar in the region of Aix-en-Provence. According to the oil manufacturer (Margier oil mill in Auriol, France), the different steps of the oil extraction process were: olive washing, grinding into a paste with a hammer mill, malaxing the olive paste at no more than $27^{\circ} \mathrm{C}$, centrifuging first to separate liquids from solids, then to separate oil from water. The olives were harvested during the 2009-2010 crop season, at two different maturity stages: olives harvested before or during color change gave olive oil of the "green fruity" type, olives harvested fully ripe and left to ferment in tightly sealed wooden crates for 4-6 days at $21-37^{\circ} \mathrm{C}$ before malaxation gave olive oil of the "black fruity" type.

\subsection{Olive oil ageing}

Samples were stored for 24 months under different storage conditions to study the effects of the five factors - oil type, oxygen, light, temperature and storage time - on the stability and quality of the oil.

To study the effect of oxygen, two sets of oil samples were placed under two predetermined conditions: (a) $40 \mathrm{~mL}$ transparent glass flasks were filled to the top with olive oil and closed, leaving a headspace of $0.5 \mathrm{~mL}$, preventing the renewal of oxygen supply; (b) $250 \mathrm{~mL}$ transparent glass flasks were each filled with $200 \mathrm{~mL}$ olive oil, leaving a headspace of $50 \mathrm{~mL}$, and at the end of each 4-month period, $25 \mathrm{~mL}$ of olive oil was withdrawn for analysis, which resulted in the renewal of the oxygen present in the headspace.

The storage conditions to study the effect of temperature were: in the refrigerator at $4{ }^{\circ} \mathrm{C}$, in a room at ambient temperature (between 18 and $30^{\circ} \mathrm{C}$ according to seasonal temperature variations), in a cupboard at $21^{\circ} \mathrm{C}$.

The storage conditions to study the effect of light exposure were: under direct light, on a windowsill; under indirect light, on a windowsill behind a shade; in the dark, in a closed box placed on a windowsill.

The oils were analysed after 4, 8, 12, 16, 20 and 24 months' storage to determine their quality indices (PV, AV, TOTOX, FA, $\mathrm{K}_{232}$, $\mathrm{K}_{270}$, Total phenols content, SFA, MUFA, and PUFA) and their infrared spectroscopic indicators $I_{\text {trans }}$ and $I_{\text {cis }}$ to quantify the double bonds in cis and trans configuration, respectively.

These analytical results were used as responses in two full-factorial experimental designs built taking into account the different levels of the factors, as summarized in Table 1. Each full-factorial design investigated two two-level factors (for "oil type" and "oxygen"), one three-level factor (for "temperature" or for "light") and one six-level factor (for "time") and included $2 \times 2 \times 3 \times 6=72$ experiments (excluding center points). These full-factorial designs were perfectly balanced, i.e., the number of experiments was the same for all the levels of a factor.

\subsection{Reagents}

Chloroform, acetic acid, diethyl ether, methanol and cyclohexane for analysis were supplied by Carlo Erba (Milan, Italy). Purex isooctane was purchased from Sigma Aldrich (Steichein, Germany). Ultrapure water was obtained from a milli-Q ultrapure water purification system (Millipore-Merck KGaA, Darmstadt, Germany). Sodium thiosulfate, methyl ester nonadecanoate, potassium iodide, and tyrosol were purchased from Sigma Aldrich. Sodium carbonate was obtained from Carlo Erba and potassium hydrogenophtalate from Prolabo (Fontenay-sous-Bois, France). Commercial p-anisidine was purchased from Alfa Aesar (Johnson Matthey Company, Karlsruhe, Germany). 
Table 1

Levels and AComDim encoding of studied factors and the associated number of experiments for the two experimental designs

\begin{tabular}{|c|c|c|c|c|c|c|c|c|c|c|c|c|c|c|}
\hline \multicolumn{15}{|l|}{ Factors } \\
\hline \multicolumn{3}{|c|}{ Oil type } & \multicolumn{3}{|c|}{ Oxygen renewal } & \multicolumn{3}{|l|}{$\underline{\text { Light }}$} & \multicolumn{3}{|c|}{ Temperature } & \multicolumn{3}{|c|}{ Storage time } \\
\hline Levels & $\mathrm{Nb}$ & Code & Levels & $\mathrm{Nb}$ & Code & Levels & $\mathrm{Nb}$ & Code & Levels & $\mathrm{Nb}$ & Code & Levels & $\mathrm{Nb}$ & Code \\
\hline \multicolumn{15}{|c|}{ First experimental design } \\
\hline Black & 36 & 1 & With & 36 & 1 & Dark & 24 & 1 & & & & 4 months & 38 & 1 \\
\hline \multirow[t]{5}{*}{ Green } & 36 & 2 & Without & 36 & 2 & Indirect light & 24 & 2 & & & & 8 months & 38 & 2 \\
\hline & & & & & & Direct light & 24 & 3 & & & & 12 months & 38 & 3 \\
\hline & & & & & & & & & & & & 16 months & 38 & 4 \\
\hline & & & & & & & & & & & & 20 months & 38 & 5 \\
\hline & & & & & & & & & & & & 24 months & 38 & 6 \\
\hline \multicolumn{15}{|c|}{ Second experimental design } \\
\hline Black & 36 & 1 & With & 36 & 1 & & & & $4{ }^{\circ} \mathrm{C}$ & 24 & 1 & 4 months & 38 & 1 \\
\hline \multirow[t]{5}{*}{ Green } & 36 & 2 & Without & 36 & 2 & & & & $21^{\circ} \mathrm{C}$ & 24 & 2 & 8 months & 38 & 2 \\
\hline & & & & & & & & & $18-30^{\circ} \mathrm{C}$ & 24 & 3 & 12 months & 38 & 3 \\
\hline & & & & & & & & & & & & 16 months & 38 & 4 \\
\hline & & & & & & & & & & & & 20 months & 38 & 5 \\
\hline & & & & & & & & & & & & 24 months & 38 & 6 \\
\hline
\end{tabular}

$\mathrm{Nb}$ : number of experiments, code: factors encoding for AComDim procedure.

\subsection{Olive oil quality}

\subsubsection{Analytical indices}

Free acidity (FA, expressed as percentage of oleic acid), peroxide value (PV, expressed as milliequivalents of active oxygen per kilogram of oil (meq $\mathrm{O}_{2} \mathrm{~kg}^{-1}$ )) and UV spectrophotometric indices $\left(\mathrm{K}_{232}, \mathrm{~K}_{270}\right)$ were assessed according to the official methods described in Regulation EC 2568/91 of the Commission of the European Union (EEC, 2013). P-anisidine value (AV) was measured according to the ISO standard method 6885 (ISO, 2006). Total oxidation value (TOTOX $=2 \mathrm{PV}+\mathrm{AV}$ ) was calculated (Poulli et al., 2009). Theses indices were determined in triplicate for each sample, and the average values were used.

\subsubsection{Total phenols content}

The total phenols content was determined according to the Folin-Ciocalteu spectrometric method at $765 \mathrm{~nm}$ (Thermo Electron Corporation Evolution 300 UV-vis spectrometer (Boston, Massachusetts, USA)) using a tyrosol calibration curve (Singleton, Orthofer, \& Lamuela-Raventos, 1999). Results were expressed as milligrams of tyrosol per kilogram of oil.

\subsubsection{Fatty acid methyl ester (FAME)}

FAMEs were analysed by capillary gas chromatography: Agilent 7890A GC System (Santa Clara, USA) equipped with a $0.25 \mu \mathrm{m} \times 60 \mathrm{~m} \times 0.25 \mathrm{~mm}$ Sulpelcowax column, with hydrogen as the carrier gas (flow rate: $1 \mathrm{~mL} / \mathrm{min}$; split ratio: $1 / 70, \mathrm{v} / \mathrm{v}$ ), and with a flame ionization detector (FID). Chromatographic parameters were as follows: injector temperature, $250^{\circ} \mathrm{C}$; detector temperature, $250{ }^{\circ} \mathrm{C}$; initial oven temperature $210^{\circ} \mathrm{C}$, maintained for $20 \mathrm{~min}, 6^{\circ} \mathrm{C} / \mathrm{min}$ temperature ramp, final oven temperature $245^{\circ} \mathrm{C}$, maintained for $17 \mathrm{~min}$. The injected volume was $1 \mu \mathrm{L}$. The data obtained were analysed using Agilent Chemstation software (REV.B.04.01). FAMEs were prepared according to a modified version of the IOC method (IOC, 2001). A solution of methyl nonadecanoate ester $\left(C_{19}, 2 \mathrm{mg} / \mathrm{mL}\right.$ in isooctane) was used as internal standard to calculate each fatty acid content in $\mathrm{mg}$ eq $\mathrm{C}_{19} \cdot \mathrm{g}^{-1}$ oil. A weighed quantity of olive oil sample (around $0.120 \pm 0.001 \mathrm{~g}$ ) was introduced into a centrifuge tube, with $2 \mathrm{~mL}$ of internal standard solution and $0.2 \mathrm{~mL}$ of cold methanolic solution of $\mathrm{KOH}(2 \mathrm{M})$, to undergo transmethylation. The mixture was stirred 2 min with a test tubes agitator, diluted with $1 \mathrm{~mL}$ of isooctane, and centrifuged at $3900 \mathrm{rpm}$ for $5 \mathrm{~min}$. An aliquot of the solvent phase was taken for injection. Peaks were identified by comparing their retention times with those of standard samples. Fatty acids were classified into three categories: saturated fatty acids (SFA), containing C16:0, C17:0, C18:0, C20:0, C22:0 and C24:0; mono-unsaturated

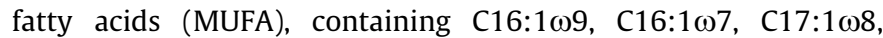
$\mathrm{C} 18: 1 \omega 9, \mathrm{C} 18: 1 \omega 7, \mathrm{C} 20: 1 \omega 9$; and polyunsaturated fatty acids (PUFA), containing C18:2 $\omega 6$ and $\mathrm{C} 18: 3 \omega 3$. The concentration $\left(C_{i}\right)$ of the methyl ester associated with each fatty acid, expressed in $\mathrm{mg} \mathrm{g}^{-1}$ eqC $\mathrm{C}_{19}$, was calculated from the following expression:

$C_{i}=\frac{A_{i} \times C_{e}}{A_{e}} \times \frac{k_{i}}{k_{e}}$

where $C_{e}$ is the internal standard concentration $\left(2 \mathrm{mg} \mathrm{mL}^{-1}\right), A_{i}$, the methyl ester peak area and $A_{e}$, the internal standard peak area. The response factors $k_{i}$ were considered identical for all the compounds and thus the ratio $k_{i} / k_{e}$ was equal to 1 .

\subsubsection{Infrared indicators}

Mid-infrared spectra $\left(4000-650 \mathrm{~cm}^{-1}, 4 \mathrm{~cm}^{-1}\right.$ resolution, 64 scans) were recorded on a Thermo Fisher Scientific IS10 spectrometer (Waltham, Massachusetts, USA) equipped with a DTGS detector, an Ever-Glo source and a $\mathrm{KBr} /$ Germanium beam splitter. Samples were deposited without preparation on the diamond crystal cell (Specac) of the Attenuated Total Reflectance (ATR) accessory. Air was taken as reference for the background spectrum (collected before each sample acquisition, under the same conditions). Two indicators were calculated from band area ratios (Le Dréau, Dupuy, Gaydou, Joachim, \& Kister, 2009). The first indicator, $I_{c i s}$, characterized the evolution of the band assigned to the cis $\mathrm{C}=\mathrm{CH}$ bond while the second one, $I_{\text {trans, }}$ characterized the evolution of the band assigned to the trans $\mathrm{C}=\mathrm{CH}$ bond. They were calculated as follows:

$I_{\text {cis }}=\frac{\left(\frac{A_{3004}}{A_{3004}+A_{2900}}\right)_{T_{t}}}{\left(\frac{A_{3004}}{A_{3004}+A_{2900}}\right)_{T_{0}}}$
$I_{\text {trans }}=\left(\frac{A_{970}}{A_{970}+A_{1450}}\right)_{T_{t}}$

where $A_{i}$ are the areas of the bands at $970 \mathrm{~cm}^{-1}$ (trans $v_{\mathrm{CH}}$ for $\mathrm{C}=\mathrm{CH}), 1450 \mathrm{~cm}^{-1}\left(\delta_{\mathrm{CH}}\right.$ for $\mathrm{CH}_{2}$ and $\left.\mathrm{CH}_{3}\right), 2900 \mathrm{~cm}^{-1}\left(v_{\mathrm{CH}}\right.$ for aliphatic $\mathrm{CH}_{2}$ and $\mathrm{CH}_{3}$ ) and $3004 \mathrm{~cm}^{-1}$ ( cis $\mathrm{v}_{\mathrm{CH}}$ for $\mathrm{C}=\mathrm{CH}$ ), measured from valley to valley in spectra of fresh olive oil $\left(T_{0}\right.$, fresh oil) and aged olive oil ( $T_{t}$ varying from 4 to 24 months). 


\subsection{AComDim}

AComDim was used in this study as a multi-block analysis that is able to highlight influential factors and their interactions by simultaneous analysis of all data. The AComDim method is based on the same concept as ANOVA-PCA (also called APCA) and its description can be found in the papers by Amat et al. (2010) and Bouveresse et al. (2011). In AComDim, the experimental data matrix is decomposed into a series of successive matrices (also called mean matrices) containing, for each factor or interaction, the mean at each level. The residuals matrix remaining after successive subtraction of all mean matrices is added back to each of them to obtain means plus residuals matrices (called blocks). Then, a multi-block analysis of all matrices is performed in order to extract the "Common Components" (CCs). Each block has a specific weight, called "salience", associated with each CC. Since all blocks contain a contribution from the residual matrix, the first Common Component CC1 (with higher saliences) contains mainly noise. To estimate the significance of a block, a Fisher test (F-test) can be applied on the $F$-values $\left(F_{i}\right)$ calculated as follows (Eq. (4)).

$F_{i}=\frac{\lambda_{\text {res }}}{\lambda_{i}}$

where $\lambda_{\text {res }}$ is the salience of the residual block on CC1 and $\lambda_{i}$ is the salience of the $i$ th block on CC1.

The $F$-test is performed by selecting $n-1$ degrees of freedom, where $n$ is the number of blocks. The significance level, so-called alpha level, is set equal to 0.05 to be considered statistically significant. The blocks for which $F_{i}$ is greater than the critical value $\left(F_{c}\right)$ of the Fisher table are considered as being related to influential factors or interactions. By examining the calculated saliences, it is possible to determine which $\mathrm{CC}$ is related to which factor or interaction.

The relative importance of a factor compared to the residual noise is related to its salience value in the CC where it has a high influence, and to the percentage of variance contained in that CC. In order to estimate the effect of the factor, it is possible to plot the sample scores on the informative CCs vs. CC1. Loadings show how data values vary along a CC and are used to understand the meaning of the scores. Loadings can have negative or positive values; so can scores. If the loading of a variable and the score of a sample on a particular CC have the same sign, they are related. The larger the scores and loadings, the stronger that relation.

All computations were performed using Matlab 7.14 (R2012a). The AComDim procedure was adapted from the ComDim function in the free toolbox SAISIR (Cordella \& Bertrand, 2014).

\section{Results and discussion}

Because of the important number of chemical indices for the different ageing conditions, not all experimental values (Plard, 2014) will be considered in this paper. Fig. 1 shows the maxima and minima of the normalized values of the chemical analyses carried out on the two olive oil sample sets. It is to be noted that whatever the oil type ("green fruity" or "black fruity") all indices evolved during the period of natural ageing. The fatty acid composition (SFA, MUFA, and PUFA) and the spectroscopic indicators ( $I_{\text {cis }}$ and $I_{\text {trans }}$ ) changed the least (Fig. 1). Tables 2 and 3 give the index values for "green fruity" oil samples and "black fruity" oil samples. It is to be noted that the index values for the fresh oil samples ( 0 month) are the mean of the values determined from ten experiments, which were used to determine the experimental error.

According to the European Regulation (EEC, 2013) and the standard error of determination of quality indices, the fresh "green fruity" oil belongs to the category of "extra virgin olive oil", whereas the fresh "black fruity" oil belongs to the category of "virgin oil", especially because of its high FA, PV and $K_{232}$ values. However, "black fruity" oil, made "as in the old days" has characteristics that, far from displeasing consumers, arouse their interest, even more so since today's producers are able to control the various manufacturing steps to produce oils of constant quality.

Before ageing, three quality indices are considered to differentiate between oil samples: free acidity, p-anisidine value and total phenols content. High free acidity is considered as a defect and can be essentially attributed to the fermentation of olives in which triglycerides are degraded, resulting in the formation of free acids. Therefore FA of the fresh "black fruity" oil ( $0.90 \%$ eq oleic acid $)$ is superior to that of fresh "green fruity" oil (FA $=0.26 \%$ eq oleic acid). The $\mathrm{p}$-anisidine value is an indicator of the content in aldehydes, formed during fermentation. However, in our case, the degradation of "black fruity" oil proceeds until the occurrence of acid forms, and so its p-anisidine value is in fact lower than that of fresh "green fruity" oil. As expected, the phenols content of the oil obtained from ripe and fermented fruit ("black fruity" oil) is lower than when the oil is obtained from the green fruit ("green fruity" oil), because phenols playing the role of anti-oxidants are consumed during fermentation. The PV index is the most affected by storage conditions, followed by AV and TOTOX, since they are mathematically related. The limit fixed by the European Regulation for extra virgin olive oil (i.e., PV $<20$ meq $\mathrm{O}_{2} \mathrm{~kg}^{-1}$ (EEC, 2013)) is exceeded for the "green fruity" oil after 4 months under all ageing conditions, except in the cupboard (12 months) and in the refrigerator (20 months). Under renewed oxygen exposure (designated "with oxygen" in the rest of the article) and at room temperature, a more or less significant PV increase is observed, depending on the

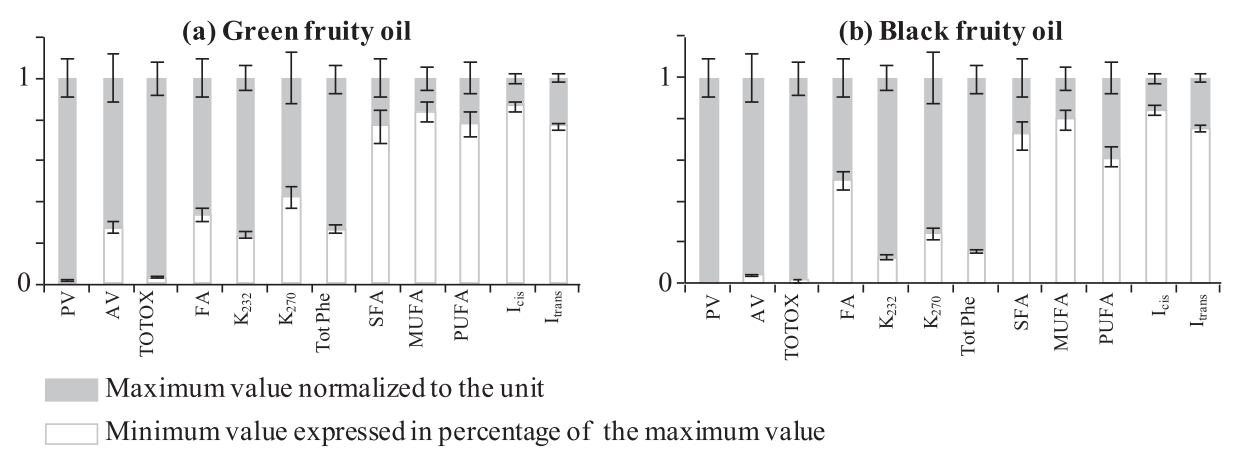

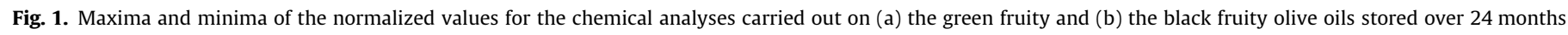
under different conditions. 
Table 2

Values of PV, AV, TOTOX, FA, $\mathrm{K}_{232}$ and $\mathrm{K}_{270}$ indices at 0,12 and 24 months for green fruity oil and black fruity oil.

\begin{tabular}{|c|c|c|c|c|c|c|c|c|c|c|c|c|c|c|c|c|c|c|}
\hline \multirow[t]{2}{*}{ Date (months) } & \multicolumn{3}{|l|}{ PV } & \multicolumn{3}{|c|}{ AV } & \multicolumn{3}{|c|}{ TOTOX } & \multicolumn{3}{|l|}{ FA } & \multicolumn{3}{|l|}{$\underline{K_{232}}$} & \multicolumn{3}{|l|}{$\mathrm{K}_{270}$} \\
\hline & 0 & 12 & 24 & 0 & 12 & 24 & 0 & 12 & 24 & 0 & 12 & 24 & 0 & 12 & 24 & 0 & 12 & 24 \\
\hline Samples & \multicolumn{18}{|c|}{ Green fruity oil } \\
\hline UV & 15 & 6 & 5 & 9 & 8 & 7 & 40 & 19 & 16 & 0.3 & 0.4 & 0.6 & 2.6 & 2.5 & 2.2 & 0.17 & 0.26 & 0.24 \\
\hline $\mathrm{L}$ & 15 & 13 & 9 & 9 & 7 & 6 & 40 & 33 & 24 & 0.3 & 0.4 & 0.6 & 2.6 & 2.6 & 2.3 & 0.17 & 0.26 & 0.24 \\
\hline $\mathrm{D}$ & 15 & 16 & 7 & 9 & 8 & 9 & 40 & 39 & 22 & 0.3 & 0.4 & 0.5 & 2.6 & 2.8 & 4.1 & 0.17 & 0.25 & 0.31 \\
\hline $\mathrm{C}$ & 15 & 16 & 15 & 9 & 8 & 8 & 40 & 40 & 37 & 0.3 & 0.3 & 0.4 & 2.6 & 2.5 & 3.0 & 0.17 & 0.19 & 0.24 \\
\hline $\mathrm{Fr}$ & 15 & 17 & 16 & 9 & 9 & 9 & 40 & 42 & 41 & 0.3 & 0.2 & 0.3 & 2.6 & 2.8 & 2.8 & 0.17 & 0.19 & 0.16 \\
\hline OUV & 15 & 35 & 70 & 9 & 7 & 17 & 40 & 76 & 157 & 0.3 & 0.4 & 0.7 & 2.6 & 3.4 & 7.6 & 0.17 & 0.26 & 0.30 \\
\hline $\mathrm{OL}$ & 15 & 45 & 93 & 9 & 6 & 17 & 40 & 96 & 203 & 0.3 & 0.5 & 0.6 & 2.6 & 3.6 & 7.5 & 0.17 & 0.27 & 0.31 \\
\hline OD & 15 & 49 & 112 & 9 & 6 & 6 & 40 & 104 & 229 & 0.3 & 0.4 & 0.5 & 2.6 & 3.3 & 4.0 & 0.17 & 0.27 & 0.32 \\
\hline $\mathrm{OC}$ & 15 & 21 & 40 & 9 & 8 & 7 & 40 & 49 & 86 & 0.3 & 0.3 & 0.4 & 2.6 & 3.4 & 4.9 & 0.17 & 0.20 & 0.29 \\
\hline \multirow[t]{2}{*}{$\mathrm{OFr}$} & 15 & 17 & 24 & 9 & 8 & 8 & 40 & 41 & 55 & 0.3 & 0.3 & 0.3 & 2.6 & 2.8 & 2.9 & 0.17 & 0.20 & 0.18 \\
\hline & \multicolumn{18}{|c|}{ Black fruity oil } \\
\hline UV & 21 & 4 & 0 & 4 & 4 & 3 & 49 & 11 & 3 & 0.9 & 1.2 & 1.4 & 2.9 & 2.5 & 2.4 & 0.17 & 0.20 & 0.20 \\
\hline $\mathrm{L}$ & 21 & 13 & 58 & 4 & 4 & 18 & 49 & 30 & 135 & 0.9 & 1.1 & 1.5 & 2.9 & 2.8 & 6.9 & 0.17 & 0.23 & 0.31 \\
\hline $\mathrm{D}$ & 21 & 18 & 13 & 4 & 4 & 5 & 49 & 40 & 31 & 0.9 & 1.1 & 1.3 & 2.9 & 3.1 & 2.8 & 0.17 & 0.24 & 0.27 \\
\hline $\mathrm{C}$ & 21 & 19 & 15 & 4 & 4 & 4 & 49 & 41 & 33 & 0.9 & 1.0 & 1.2 & 2.9 & 3.1 & 2.6 & 0.17 & 0.19 & 0.21 \\
\hline $\mathrm{Fr}$ & 21 & 22 & 21 & 4 & 3 & 4 & 49 & 47 & 47 & 0.9 & 0.9 & 1.0 & 2.9 & 3.2 & 3.1 & 0.17 & 0.18 & 0.15 \\
\hline OUV & 21 & 27 & 49 & 4 & 5 & 13 & 49 & 58 & 109 & 0.9 & 1.2 & 1.6 & 2.9 & 3.6 & 7.0 & 0.17 & 0.23 & 0.29 \\
\hline $\mathrm{OL}$ & 21 & 37 & 98 & 4 & 5 & 17 & 49 & 79 & 212 & 0.9 & 1.1 & 1.5 & 2.9 & 3.8 & 9.5 & 0.17 & 0.22 & 0.34 \\
\hline OD & 21 & 57 & 135 & 4 & 3 & 5 & 49 & 117 & 273 & 0.9 & 1.1 & 1.3 & 2.9 & 3.5 & 5.2 & 0.17 & 0.26 & 0.30 \\
\hline OC & 21 & 33 & 48 & 4 & 3 & 4 & 49 & 69 & 100 & 0.9 & 1.0 & 1.2 & 2.9 & 3.9 & 6.1 & 0.17 & 0.20 & 0.29 \\
\hline $\mathrm{OFr}$ & 21 & 26 & 30 & 4 & 2 & 4 & 49 & 54 & 64 & 0.9 & 0.9 & 0.9 & 2.9 & 3.2 & 7.0 & 0.17 & 0.23 & 0.15 \\
\hline
\end{tabular}

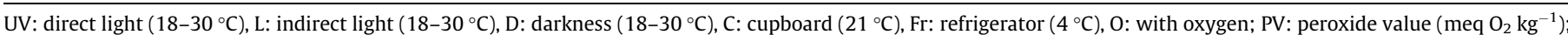
AV: p-anisidine value; TOTOX: total oxidation value; FA: free acidity (\% oleic acid); $\mathrm{K}_{232}$ and $\mathrm{K}_{270}$ : spectrophotometric indices at 232 and 270 nm.

Table 3

Values of total phenols content, SFA, MUFA, PUFA, $I_{\text {cis }}$ and $I_{\text {trans }}$ indices at 0,12 and 24 months for green fruity oil and black fruity oil.

\begin{tabular}{|c|c|c|c|c|c|c|c|c|c|c|c|c|c|c|c|c|c|c|}
\hline \multirow[t]{2}{*}{ Date (months) } & \multicolumn{3}{|c|}{ Total phe } & \multicolumn{3}{|l|}{ SFA } & \multicolumn{3}{|c|}{ MUFA } & \multicolumn{3}{|c|}{ PUFA } & \multicolumn{3}{|l|}{$I_{\text {cis }}$} & \multicolumn{3}{|l|}{$I_{\text {trans }}$} \\
\hline & 0 & 12 & 24 & 0 & 12 & 24 & 0 & 12 & 24 & 0 & 12 & 24 & 0 & 12 & 24 & 0 & 12 & 24 \\
\hline Samples & \multicolumn{18}{|c|}{ Green type oil } \\
\hline UV & 480 & 420 & 342 & 154 & 134 & 150 & 724 & 713 & 692 & 96 & 95 & 91 & 1.00 & 0.99 & 0.98 & 0.07 & 0.07 & 0.07 \\
\hline $\mathrm{L}$ & 480 & 392 & 362 & 154 & 136 & 147 & 724 & 725 & 679 & 96 & 96 & 90 & 1.00 & 0.99 & 0.98 & 0.07 & 0.07 & 0.07 \\
\hline D & 480 & 476 & 408 & 154 & 137 & 151 & 724 & 730 & 698 & 96 & 97 & 93 & 1.00 & 0.99 & 0.98 & 0.07 & 0.07 & 0.07 \\
\hline $\mathrm{C}$ & 480 & 327 & 370 & 154 & 134 & 151 & 724 & 717 & 697 & 96 & 95 & 92 & 1.00 & 0.98 & 0.99 & 0.07 & 0.07 & 0.07 \\
\hline $\mathrm{Fr}$ & 480 & 452 & 443 & 154 & 119 & 154 & 724 & 650 & 723 & 96 & 86 & 96 & 1.00 & 1.01 & 0.98 & 0.07 & 0.07 & 0.07 \\
\hline OUV & 480 & 222 & 207 & 154 & 123 & 149 & 724 & 652 & 674 & 96 & 85 & 79 & 1.00 & 0.98 & 0.94 & 0.07 & 0.07 & 0.08 \\
\hline $\mathrm{OL}$ & 480 & 339 & 180 & 154 & 130 & 149 & 724 & 692 & 681 & 96 & 90 & 81 & 1.00 & 0.97 & 0.94 & 0.07 & 0.07 & 0.08 \\
\hline OD & 480 & 403 & 487 & 154 & 130 & 151 & 724 & 690 & 687 & 96 & 91 & 89 & 1.00 & 0.99 & 0.96 & 0.07 & 0.08 & 0.09 \\
\hline OC & 480 & 391 & 351 & 154 & 137 & 149 & 724 & 735 & 688 & 96 & 96 & 88 & 1.00 & 0.98 & 0.97 & 0.07 & 0.07 & 0.08 \\
\hline \multirow[t]{2}{*}{$\mathrm{OFr}$} & 480 & 513 & 459 & 154 & 135 & 151 & 724 & 718 & 694 & 96 & 95 & 92 & 1.00 & 0.99 & 0.97 & 0.07 & 0.07 & 0.09 \\
\hline & \multicolumn{18}{|c|}{ Black type oil } \\
\hline UV & 182 & 127 & 152 & 156 & 137 & 154 & 687 & 704 & 674 & 100 & 103 & 98 & 1.00 & 0.99 & 0.99 & 0.07 & 0.07 & 0.07 \\
\hline $\mathrm{L}$ & 182 & 180 & 143 & 156 & 136 & 155 & 687 & 697 & 669 & 100 & 101 & 88 & 1.00 & 1.00 & 0.95 & 0.07 & 0.07 & 0.07 \\
\hline D & 182 & 260 & 167 & 156 & 139 & 156 & 687 & 708 & 687 & 100 & 103 & 100 & 1.00 & 1.02 & 0.99 & 0.07 & 0.07 & 0.07 \\
\hline$C$ & 182 & 237 & 163 & 156 & 142 & 160 & 687 & 726 & 699 & 100 & 106 & 102 & 1.00 & 1.01 & 0.99 & 0.07 & 0.07 & 0.07 \\
\hline $\mathrm{Fr}$ & 182 & 177 & 184 & 156 & 140 & 153 & 687 & 718 & 675 & 100 & 105 & 99 & 1.00 & 1.01 & 1.00 & 0.07 & 0.07 & 0.07 \\
\hline OUV & 182 & 177 & 80 & 156 & 132 & 156 & 687 & 675 & 671 & 100 & 97 & 86 & 1.00 & 0.98 & 0.94 & 0.07 & 0.07 & 0.08 \\
\hline $\mathrm{OL}$ & 182 & 130 & 84 & 156 & 132 & 153 & 687 & 672 & 660 & 100 & 96 & 83 & 1.00 & 0.98 & 0.93 & 0.07 & 0.07 & 0.08 \\
\hline OD & 182 & 223 & 115 & 156 & 138 & 153 & 687 & 707 & 662 & 100 & 102 & 94 & 1.00 & 1.00 & 0.97 & 0.07 & 0.07 & 0.09 \\
\hline OC & 182 & 104 & 221 & 156 & 140 & 153 & 687 & 715 & 669 & 100 & 103 & 94 & 1.00 & 1.01 & 0.98 & 0.07 & 0.07 & 0.08 \\
\hline $\mathrm{OFr}$ & 182 & 207 & 156 & 156 & 137 & 156 & 687 & 708 & 685 & 100 & 103 & 100 & 1.00 & 1.01 & 0.98 & 0.07 & 0.07 & 0.09 \\
\hline
\end{tabular}

UV: direct light $\left(18-30^{\circ} \mathrm{C}\right)$, L: indirect light $\left(18-30^{\circ} \mathrm{C}\right)$, D: dark $\left(18-30^{\circ} \mathrm{C}\right), \mathrm{C}: 21^{\circ} \mathrm{C}$, Fr: $4{ }^{\circ} \mathrm{C}$, O: with oxygen.

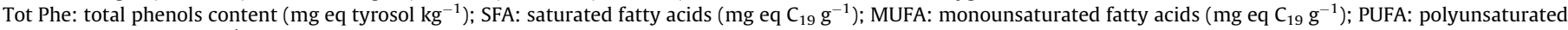
fatty acids ( $m g$ eq $\mathrm{C}_{19} \mathrm{~g}^{-1}$ ); $\mathrm{I}_{\text {trans }}$ and $\mathrm{I}_{\mathrm{cis}}$ : infrared spectroscopic indicators.

light intensity. Without oxygen, PV slowly decreases (down to zero for "black fruity" oil) for oil samples exposed to direct light for 24 months. With oxygen at ambient temperature under light exposure, AV increases whereas it remains constant without oxygen. Therefore, as expected, the FA index increases. The spectroscopic index $\mathrm{K}_{232}$ increases with oxygen and even more under direct as well as indirect light, reflecting the formation of oxidation products containing conjugated dienes. Without oxygen, $\mathrm{K}_{232}$ does not change. The total phenols content decreases when samples are exposed to light and oxygen. This behavior is less pronounced for the "black fruity" oil because its initial total phenols content is lower than for the "green fruity" oil. The other indices, $K_{270}$, SFA,
MUFA, PUFA and infrared indicators, showed less significant changes.

A global analysis of differently evolving quality indices is difficult. That is why the data were treated using AComDim, which gave quantitative information about the variability of the quality indices resulting from the effect of oil type, oxygen, storage time, light and temperature. As some experimental conditions were not carried out (no oil samples kept in the freezer under direct light, for example), an unbalanced full factorial design was obtained. So, to perform the AComDim analysis, two balanced full factorial designs were constructed, considering only 4 factors. The AComDim procedure, used for the calculations, was applied to up 
to 3-factor interactions, leading to four main factors, six 2-factor interactions, four 3-factor interactions and the residual. As the number of CCs must be sufficient enough in order to plot the scores for each factor and interaction, their minimum number was equal to the number of blocks, in the present case, fifteen. They were calculated from a data matrix of 72 samples for each balanced experimental design.
The AComDim analysis of the responses of the first experimental design (considering four factors: oil type, oxygen, storage time and light) gives the salience values of fifteen blocks on each CC. In the AComDim method, CC1 characterizes the residual noise; its salience is the highest for the residuals block (the 15th block) (Fig. 2b). The F-values are computed from the saliences on CC1 (Fig. 2a) as the ratios between the salience of the residual block
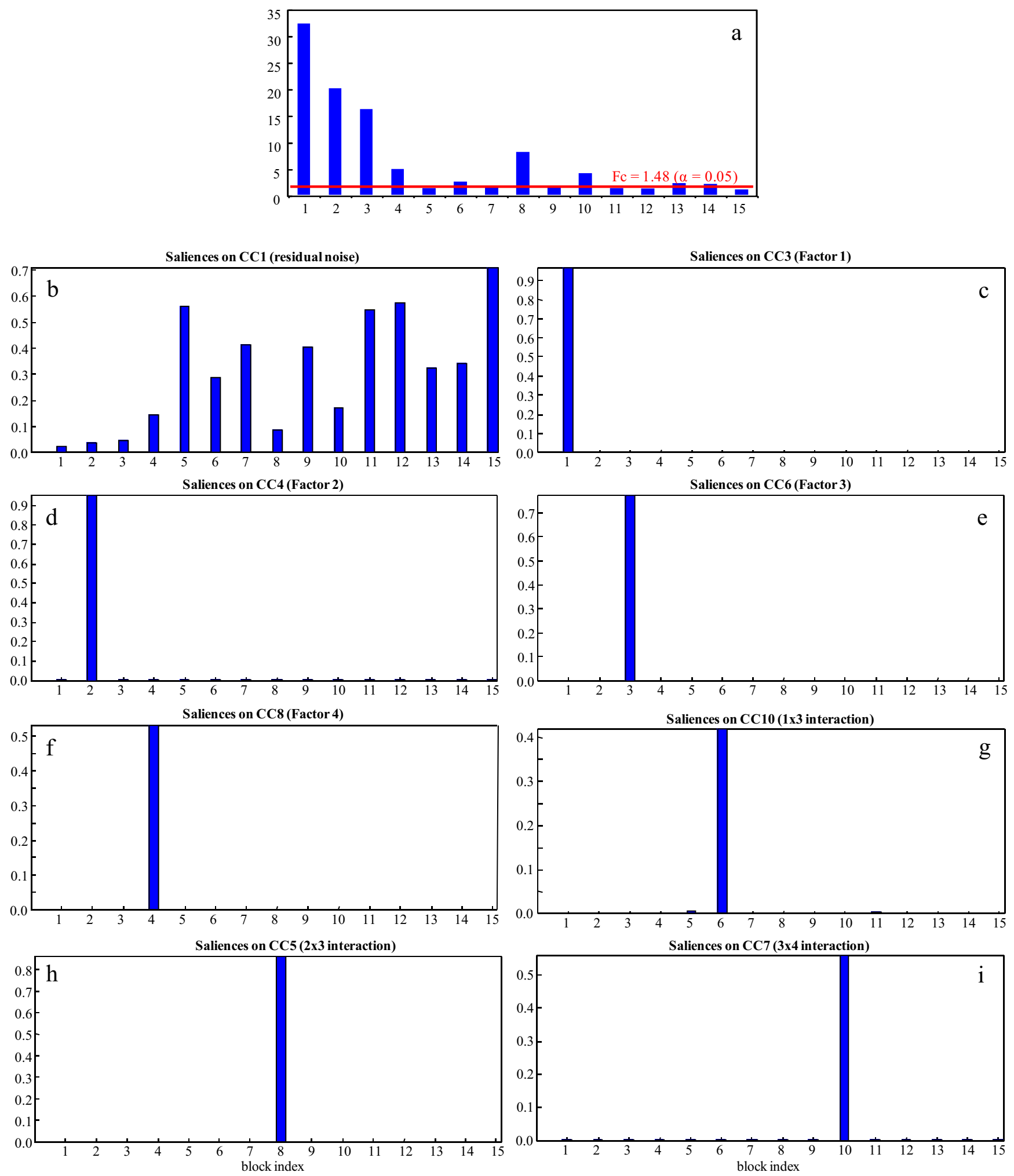

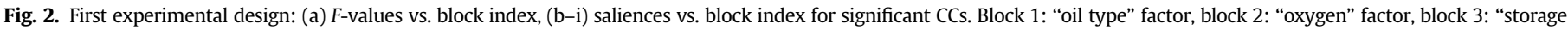
time" factor, block 4: "light" factor, block 6: "oil type $\times$ storage time" interaction, block 8: " oxygen $\times$ storage time" interaction, block 10 : "storage time $\times$ light" interaction. 
(the $15^{\mathrm{h}}$ block) and the salience of each other block. As shown on Fig. 2a, block 1 ("oil type" factor), block 2 ("oxygen" factor), block 3 ("storage time" factor), block 4 ("light" factor), block 6 ("oil type $\times$ storage time" interaction), block 8 ("oxygen $\times$ storage time" interaction) and block 10 ("light $\times$ storage time" interaction) have large $F$-values $(32.34,20.10,16.22,4.90,2.45,8.12$ and 4.10,

Factor 1 "oil type"
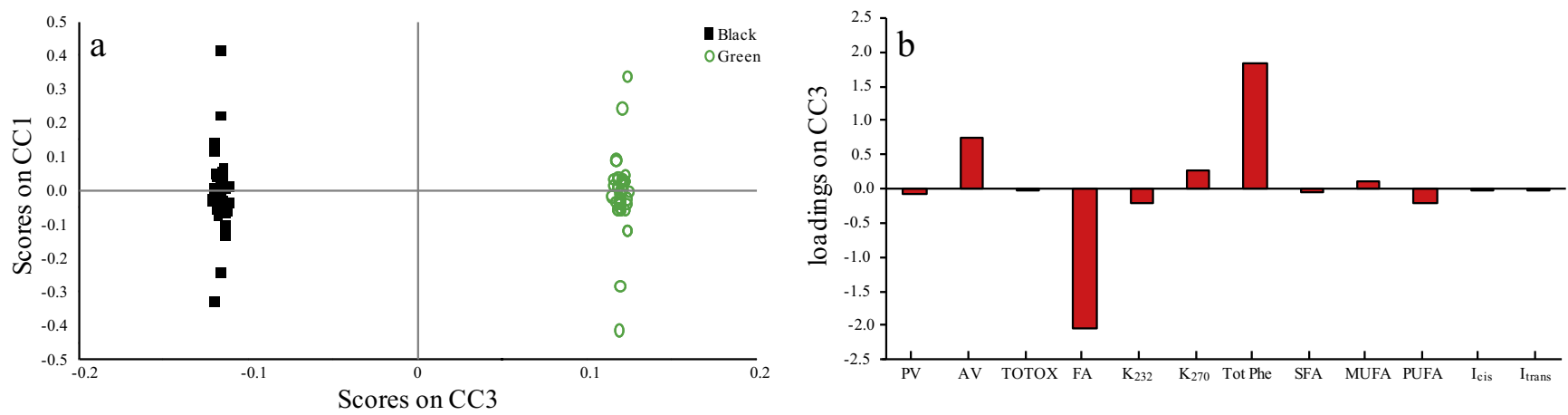

Factor 2"oxygen"
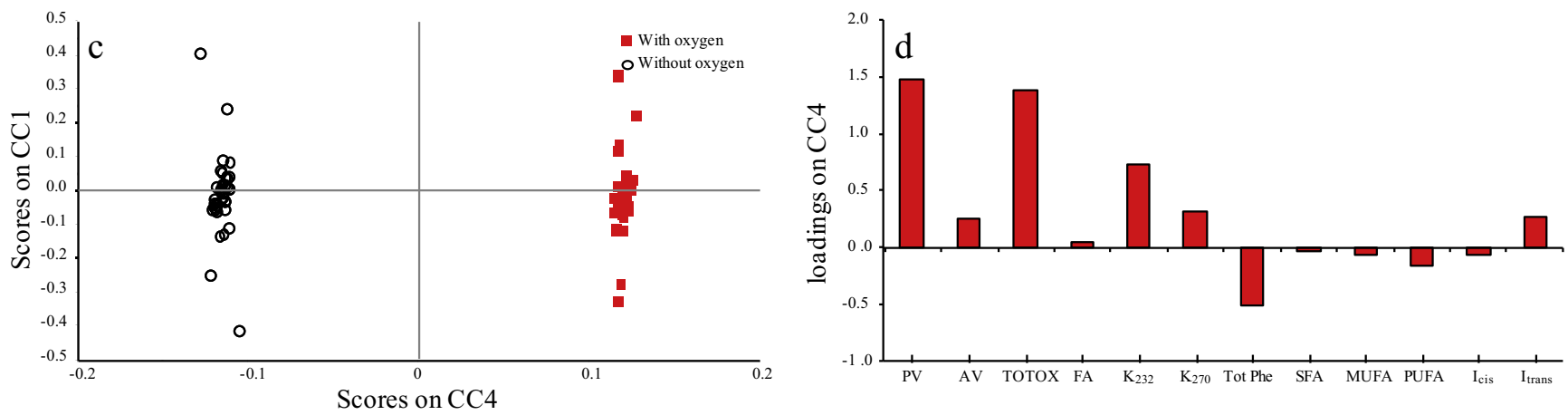

Factor 3 "storage time"
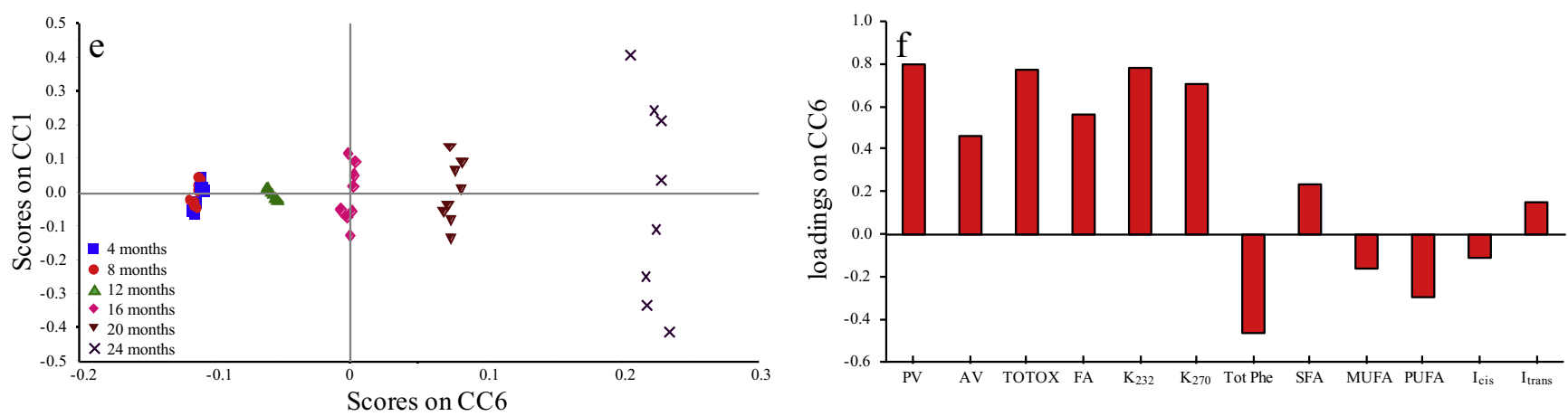

Factor 4 "light"
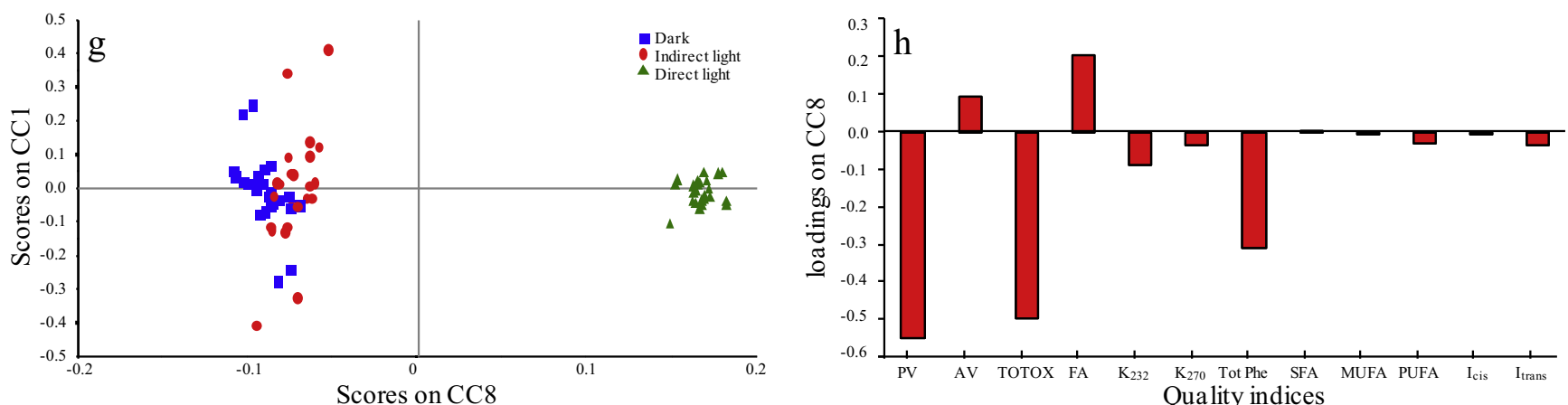

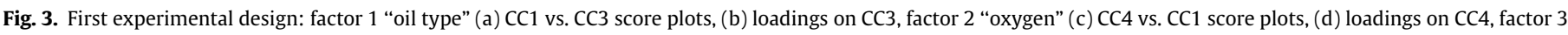

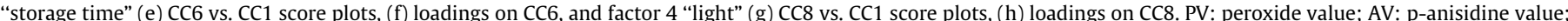

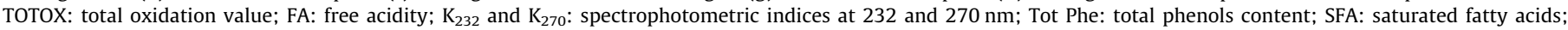
MUFA: monounsaturated fatty acids; PUFA: polyunsaturated fatty acids; $I_{\text {trans }}$ and $I_{\text {cis }}$ : infrared spectroscopic indicators. 
respectively) compared to the critical value $\left(F_{c}=1.48\right)$ of the Fisher table $(\alpha=0.05,71$ degrees of freedom). The $F$-values for all the other blocks are close to or smaller than $F_{c}$. Therefore, the probability is great that there are significant data variations in blocks $1,2,3$, $4,6,8$ and 10 , due to the corresponding factor or interaction. CC3, CC4, CC6, CC8, CC10, CC5 and CC7 have, for one of the above mentioned blocks, a much larger salience than all the other blocks (Fig. 2c-i respectively); each of these CCs is therefore significantly influenced by this block, and this can be related to the clusters observed in the corresponding score plots (CCs vs. CC1) and to the associated loadings on CCs, as seen in Fig. 3. CC3 corresponds to block 1, which is associated with the oil type. The CC3 vs. CC1 score plot shows samples are well separated according to the oil type (Fig. 3a). The "black fruity" oil samples, projected in the negative part of CC3 in the score plot, are characterized by a free acidity index seen in the negative part of the loadings on CC3 (Fig. 3b).
The total phenols content index, in the positive part of the loadings on CC3, is characteristic of the "green fruity" oil samples and indicates a higher antioxidant activity than that of the "black fruity" oil. On the basis of their loadings, the other indices do not contribute much to the discrimination between oil types. FA and total phenols content appear here as markers of the stages of maturity and fermentation of the olive fruits. The other score plots in Fig. 3 appear as an interesting graphic tool to determine the specific chemical markers characterizing ageing, independently of the oil type. On the CC4 vs. CC1 score plot (Fig. 3c), samples are differentiated according to the oxygen factor. The samples with oxygen are projected on the positive side of CC4 in the score plot. The samples without oxygen are projected on the negative side. The associated loadings (Fig. $3 \mathrm{~d}$ ) show that PV, AV, TOTOX, $\mathrm{K}_{232}, \mathrm{~K}_{270}$ and $I_{\text {trans }}$ (on the positive side of the loadings plot) are characteristic of oxidized oils and are the indices whose values change the most

"oil type x storage time" interaction
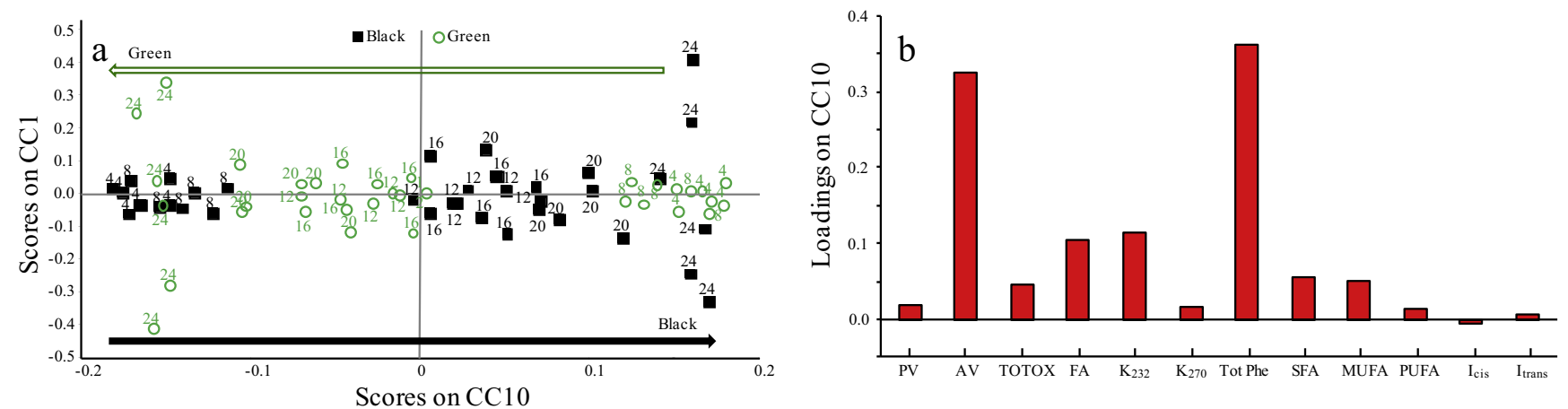

"oxygen $\mathrm{x}$ storage time" interaction
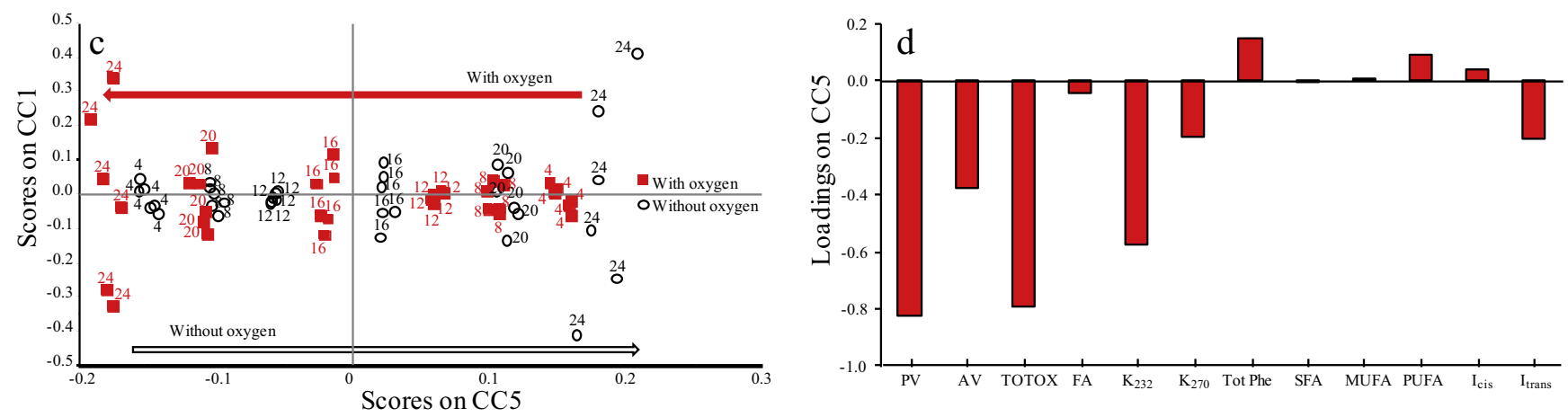

"light x stora ge time" interaction
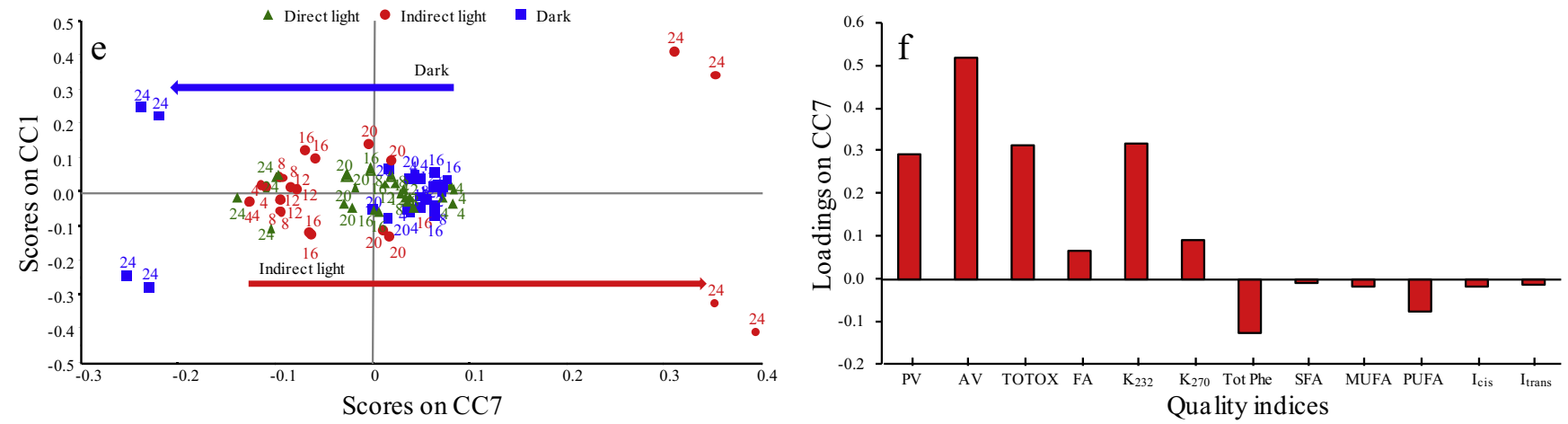

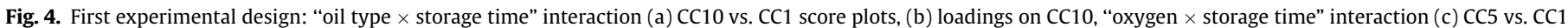

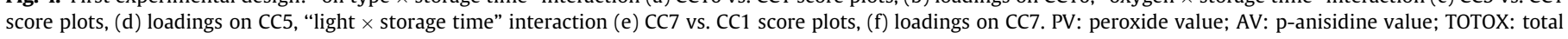

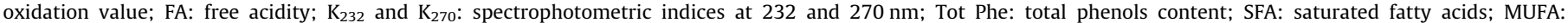

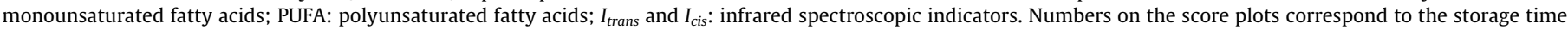
(months). 


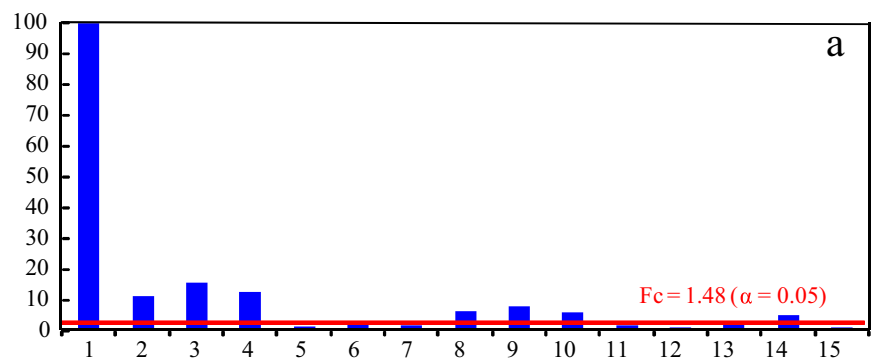

Saliences on CC1 (residual noise)
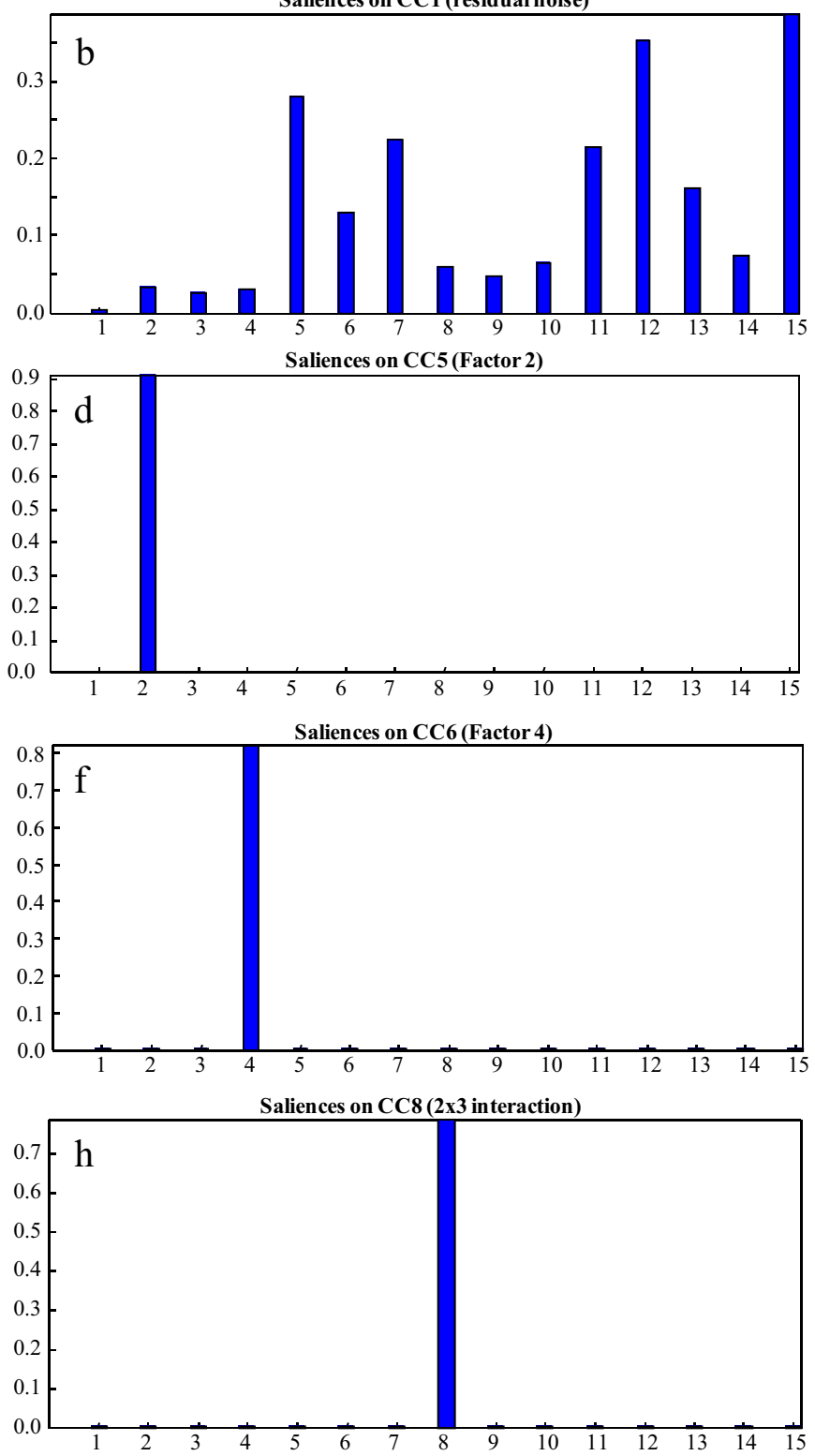

Saliences on CC4 (Factor 1$)$
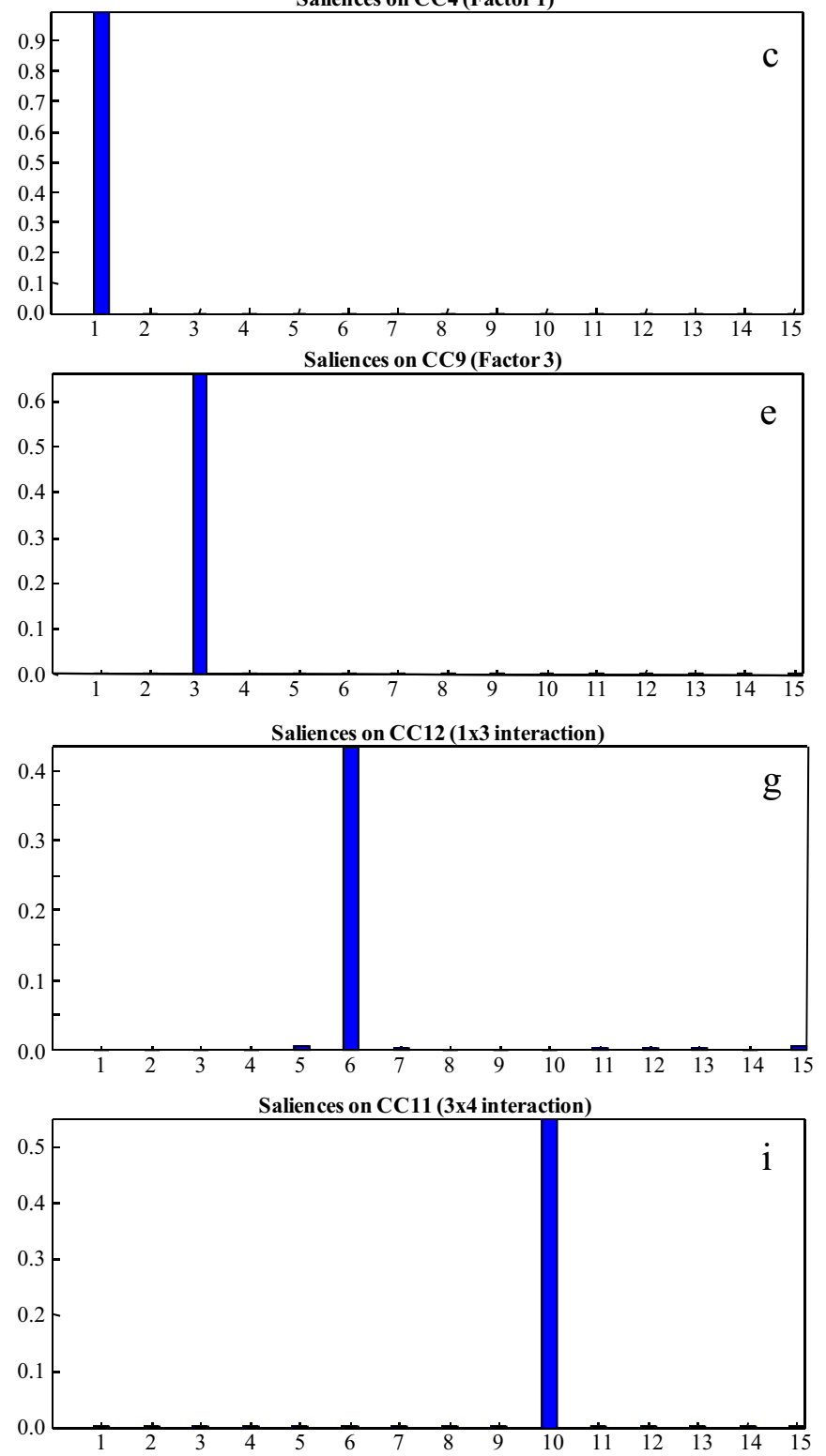

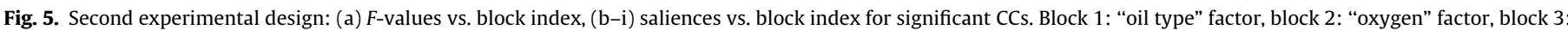

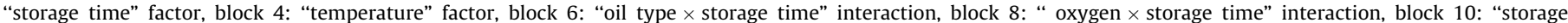
time $\times$ temperature" interaction.

with oxygen, whatever the storage conditions. This confirms the observations of the various authors who have studied the natural aging of olive oils (Gomez-Alonso et al., 2007; Naz, Siddiqi, Sheikh, \& Asad Sayeed, 2005; Psomiadou \& Tsimidou, 1998). The most significant marker is the PV index: its variations are due to the formation of primary metabolites, i.e., peroxides and hydroperoxides. Secondary metabolites, i.e., aldehydes and acid forms, are not in sufficient concentrations to be considered as indicator species for monitoring the effect of oxygen on oil ageing. Examination of the CC6 vs. CC1 score plot (Fig. 3e) reveals a good distribution of the samples according to storage time: the longest storage times induce the largest score values. Samples stored for 
4 and 8 months are projected in two clusters on the negative side of the score plot while samples stored for 24 months are projected on the positive side. This repartition shows an impact of the storage time, becoming increasingly important after 8 months' storage. The positive side of the loadings on CC6 (Fig. 3f) shows that PV, AV, TOTOX, FA, $\mathrm{K}_{232}, \mathrm{~K}_{270}$, SFA and $I_{\text {trans }}$ are characteristic

Factor 1 "oil type"
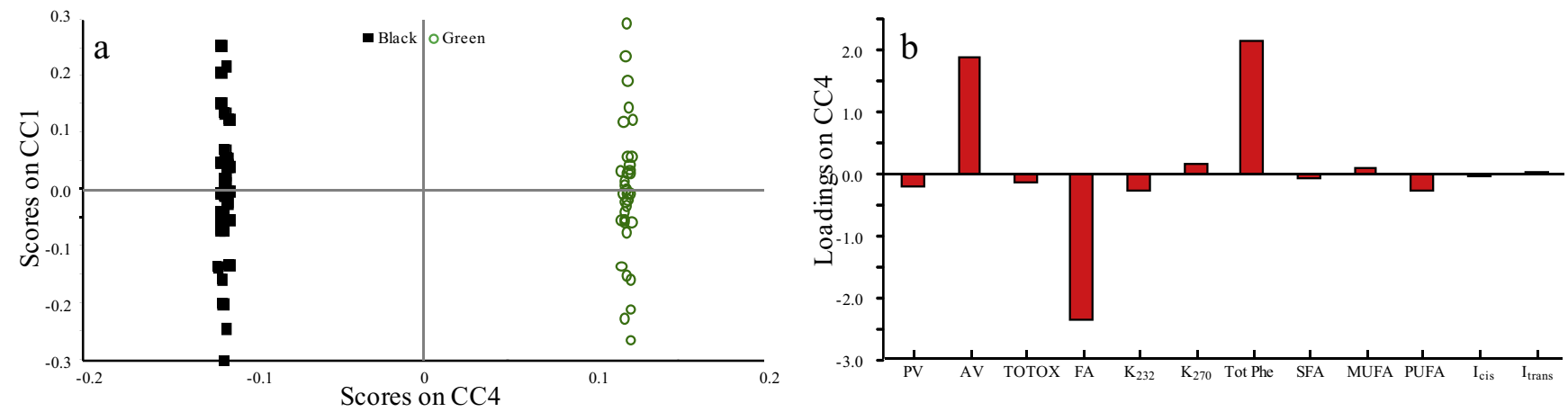

Factor 2 "oxygen"
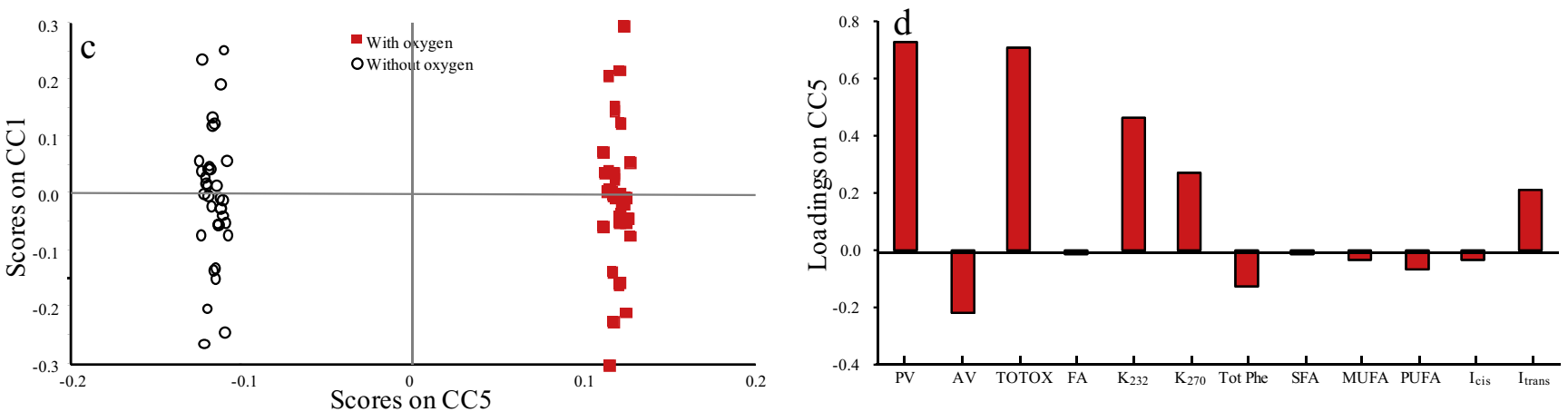

Factor 3 "storage time"
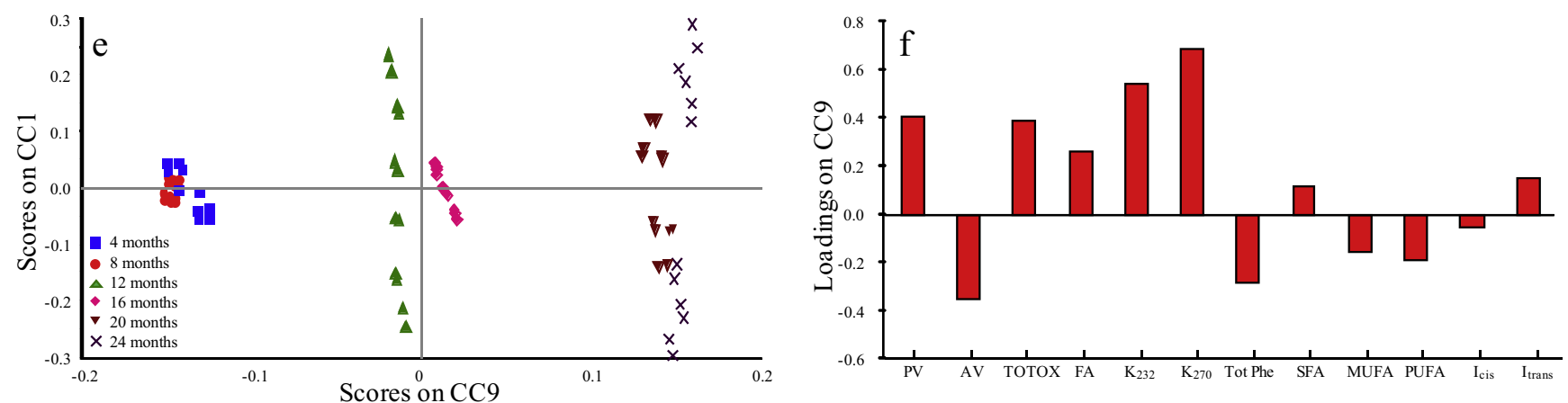

Factor 4 "temperature"
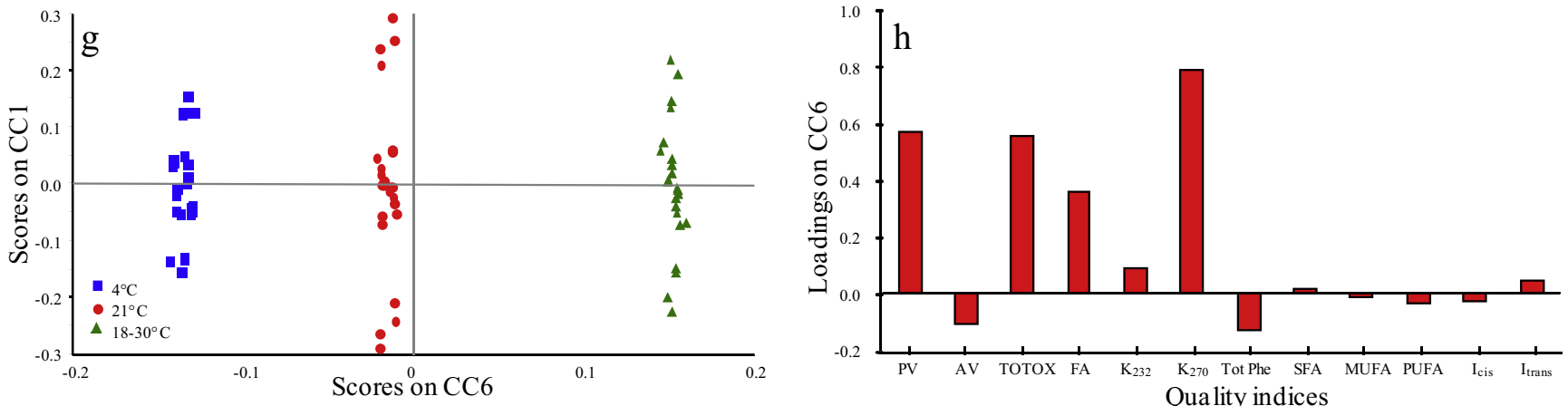

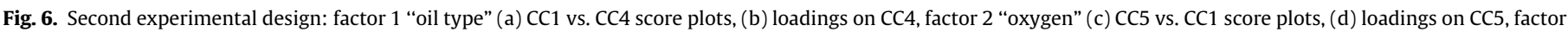

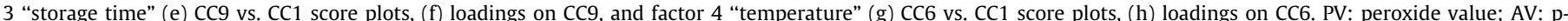

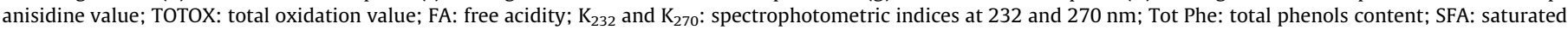
fatty acids; MUFA: monounsaturated fatty acids; PUFA: polyunsaturated fatty acids; $I_{\text {trans }}$ and $I_{\text {cis }}$ : infrared spectroscopic indicators. 
of the samples more than 16 months of age. Under almost all ageing conditions, the values of these quality indices increase with the storage time. According to the equal loadings of PV and FA, storage time influences the formation of primary and secondary metabolites (hydroperoxides and acids forms, respectively) in the same proportions. When storage time is less than 16 months, the total phenols content is high. It starts to decrease from 16 months for both oil types and for all ageing conditions. The impact of the storage time is also visible on MUFA and PUFA, but to a lesser extent. The CC8 vs. CC1 score plot shows a clear separation between samples according to light (Fig. $3 \mathrm{~g}$ ). The oil samples exposed under direct light, projected on the positive side of the $\mathrm{CC} 8$, have a different behavior than the others (projected on the negative side of the CC8). According to the loadings on CC8 (Fig. 3h), samples stored under direct light are mainly characterized by an increasing FA. Other samples are essentially differentiated on the basis of their PV values (consequently TOTOX values) and total phenols content.
Moreover, AComDim on quality indices values shows three significant 2-factor interactions. The first scores plot (Fig. 4a) shows the repartition of samples according to the "oil type $\times$ storage time" interaction. On CC10, the scores evolve oppositely over time, for the two oils and reveal that the oils behave differently during storage. According to the loadings on CC10 (Fig. 4b), AV index and the total phenols content are two significant indices: the important loadings of these indices show that during storage these two indices increase for "black fruity" oil, while in the case of "green fruity" oil, they do not evolve. On the CC5 vs. CC1 score plot (Fig. 4c), samples are grouped according to the ageing period and evolve oppositely in the presence or absence of oxygen. The "oxygen $\times$ storage time" combination modifies significantly the quality indices (Fig. 4d) for the samples projected in the negative part of the CC5 (particularly PV, TOTOX and $\mathrm{K}_{232}$ indices) while the evolutions of total phenols content and PUFA are smaller for the samples projected in the positive part of CC5. This means that
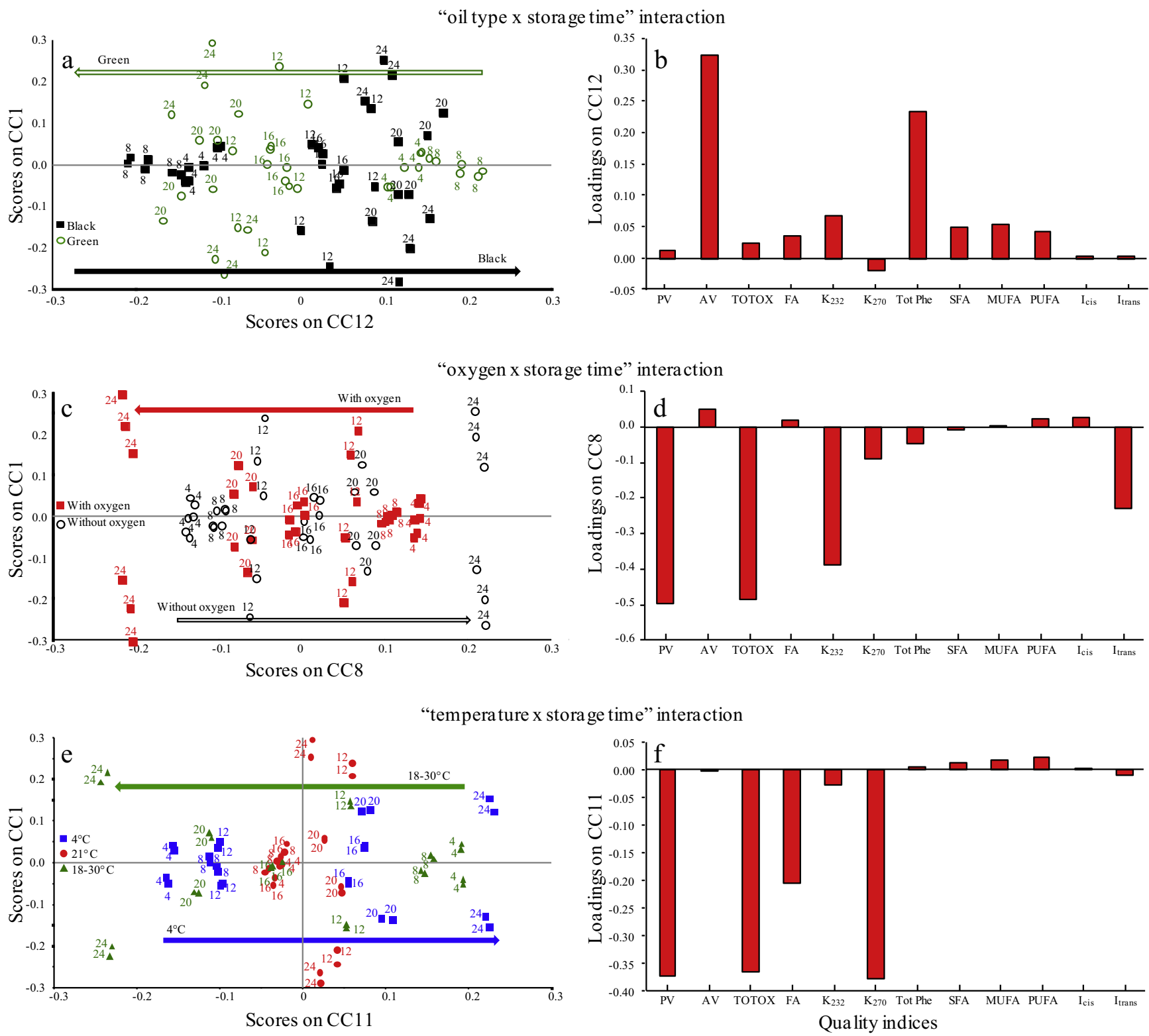

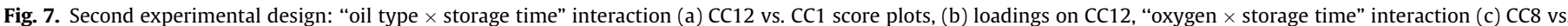

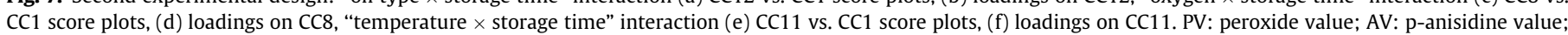

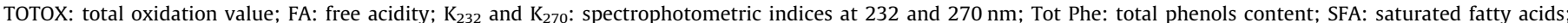

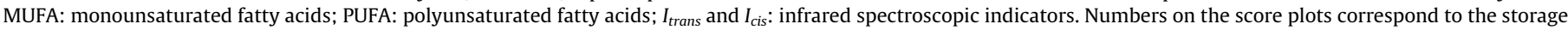
time (months). 
during storage, PV, TOTOX, $\mathrm{K}_{232}$ indices increased with oxygen, which is in agreement with the results of Del Caro, Vacca, Poiana, Fenu, and Piga (2006) and Mendez and Falqué (2007) while they remained constant without oxygen, as described by $\mathrm{Di}$ Giovacchino et al. (2002) and by Caponio, Tersa-Bilancia, Pasqualone, Sikorska, and Gomes (2005). The total phenols content appears to be the most significantly influenced by storage without oxygen but its values change slightly (low positive loading). Concerning the "light $\times$ storage time" interaction (Fig 4e), only the oil samples left to age for 24 months under indirect light and in the dark are differentiated from the others. The samples projected in the positive part of CC7 see a major change in their quality indices, especially the p-anisidine value (positive loadings on CC7, Fig. 4f). All the significant indices increased for 24 months under indirect light. In the dark for 24 months, they did not evolve or decreased weakly, as described by Del Caro et al. (2006) but the total phenols content and PUFA indices somewhat increased. The impact of storage time appears more significant than that of light.

To study the influence of temperature, the AComDim analysis was carried out on the second experimental design (oil type, oxygen, storage time and temperature). According to Fig. 5, blocks 1 ("oil type"), 2 ("oxygen"), 3 ("storage time"), 4 ("temperature"), 6 ("oil type $\times$ storage time"), 8 ("oxygen $\times$ storage time"), 9 ("oxygen $\times$ temperature") and 10 ("storage time $\times$ temperature") have an $F$-value higher than $F_{c}$ (1.48). For the "oil type" factor (Fig. 6a and b), interpretations are similar to those made for the first experimental design. For the three other factors, oil samples are grouped according to the factor levels (Fig. 6c, e and g). Oil samples ageing under the most oxidant conditions (oxygen, variable temperature and long storage time) are projected in the positive part of the corresponding score plots and are characterized by an increase in the legal quality indices. AV and total phenols content characterize the oil samples stored in the refrigerator, without oxygen for a short storage time. For the "oil type $\times$ storage time" interaction (Fig. 7a and b), interpretations are the same as for the first experimental design. Concerning the "oxygen $\times$ storage time" interaction (Fig. 7c), only a modification of the loadings on CC8 (Fig. 7d) is observed with an inversion of the positions of AV and total phenols content, due to the absence of light. On the CC11 vs. CC1 score plot of the "storage time $\times$ temperature" interaction (Fig. 7e), all samples stored at $21^{\circ} \mathrm{C}$ are grouped in the center, while samples stored at higher temperatures $\left(18-30^{\circ} \mathrm{C}\right)$ are distributed from the right side to the left side according to storage time, and conversely for those stored at lower temperatures $\left(4{ }^{\circ} \mathrm{C}\right)$. In fact, the effect of the storage temperature was only observed after 20 months. Consequently, a high temperature $\left(18-30{ }^{\circ} \mathrm{C}\right)$ led to an increase in PV, TOTOX, FA and $\mathrm{K}_{270}$ indices (negative loadings on CC11, Fig. 7f).

According to all these results, it appears that, apart from the oil type, the other factors (oxygen, light and storage time) had significant effects on the oil quality. Moreover, the "storage time" factor was always present in the significant 2-factor interaction, as was the case for the first experimental design. Keeping oil in the dark is essential but efficient only during a limited period. A low storage temperature $\left(4^{\circ} \mathrm{C}\right)$ does not appear as the solution to fight against the effects of time. The absolute values of PV and total phenols content loadings were always high, and thus, peroxides and phenols could be considered as the principal compounds to be measured in order to evaluate the oil ageing.

\section{Conclusion}

In this work, five factors affecting the olive oil stability were investigated (olive oil type, oxygen, light, temperature and storage time). In order to highlight the effect of these influential factors and their interactions on the quality indices of oil samples left to age under different storage conditions, the AComDim method was used in two steps on two full factorial experimental designs. The five factors and some 2-factor interactions (combining the storage time with the other factors) were shown to have a significant influence on the oil conservation according to the $F$-values graph. The common components CCs were selected on the basis of the higher saliences for these factors or interactions. It was possible to visualize sample clusters according to influential factors on the CC vs. CC1 score plots. The interpretation of the corresponding loadings plots revealed significant quality indices. "Green fruity" oil and "black fruity" oil were differentiated according to FA, AV and total phenols content. Oxygen had a significant influence on PV, TOTOX, $\mathrm{K}_{232}$ and $I_{\text {trans }}$ and its impact increased over time. Direct light had more influence on AV and FA. The combined effect of temperature and storage time was mainly significant for 24 month-storage. The extreme storage temperatures $\left(4{ }^{\circ} \mathrm{C}\right.$ and $18-30^{\circ} \mathrm{C}$ ) acted differently on the evolution over time of $\mathrm{PV}$, TOTOX, FA, $\mathrm{K}_{270}$ and total phenols content. This work has highlighted that, during oil ageing, PV and total phenols content could always be used as markers for the occurrence of primary oxidation compounds and antioxidant compounds, respectively.

\section{References}

Amat, S., Dupuy, N., Kister, J., \& Rutledge, D. N. (2010). Development of near infrared sensors: Detection of influential factors by the AComDim method. Analytica Chimica Acta, 675, 16-23.

Bendini, A., Cerretani, L., Salvador, M. D., Fregapane, G., \& Lercker, G. (2010). Stability of the sensory quality of virgin olive oil during storage an overview. Italian Food E' Beverage Technology, 21, 389-406.

Bouchaala, F. C., Lazzez, A., Jabeur, H., Daoud, L., \& Bouaziz, M. (2014). Physicochemical characteristics of extra virgin olive oil in function of tree age and harvesting period using chemometric analysis. Scientia Horticulturae, 180, 52-58.

Bouveresse, D. J. R., Pinto, R. C., Schmidtke, L. M., Locquet, N., \& Rutledge, D. N. (2011). Identification of significant factors by an extension of ANOVA-PCA based on multi-block analysis. Chemometrics and Intelligent Laboratory Systems, 106, 173-182.

Bucci, R., Magrí, A. D., Magrí, A. L., Marini, D., \& Federico Marini, F. (2002). Chemical authentication of extra virgin olive oil varieties by supervised chemometric procedures. Journal of Agricultural and Food Chemistry, 50, 413-418.

Caponio, F., Tersa-Bilancia, M., Pasqualone, A., Sikorska, E., \& Gomes, T. (2005). Influence of the exposure to light on extra virgin olive oil quality during storage. European Food Research and Technology, 221, 92-98.

Casal, S., Malheiro, R., Sendas, A., Oliveira, B. P. P., \& Pereira, J. A. (2010). Olive oil stability under deep-frying conditions. Food and Chemical Toxicology, 48, 2972-2979.

Cordella, C. B. Y., \& Bertrand, D. (2014). SAISIR: A new general chemometric toolbox. TrAC Trends in Analytical Chemistry, 54, 75-82.

Del Caro, A., Vacca, V., Poiana, M., Fenu, P., \& Piga, A. (2006). Influence of technology, storage and exposure on components of extra virgin olive oil (Bosana cv) from whole and de-stoned fruits. Food Chemistry, 98, 311-316.

Di Giovacchino, L., Mucciarella, M. R., Costantini, N., Ferrante, M. L., Surricchio, G., \& Sestili, S. (2002). Virgin olive oil storage and stability. Acta Horticulturae, 586, 567-569.

EEC (2013). Characteristics of olive oil and olive-residue oil and on the relevant methods of analysis. Commission implementing regulation (EU) 299/2013 of March 26, 2013 amending regulation EEC 2568/91. Official journal of the European Communities, L90, 52-70.

Gomez-Alonso, S., Mancebo-Campos, V., Desamparados Salvador, M., \& Fregapane, G. (2007). Evolution of major and minor components and oxidation indices of virgin olive oil during 21 months storage at room temperature. Journal of Food Chemistry, 100, 36-42.

Harrington, P. de B., Vieira, N. E., Espinoza, J., Nien, J. K., Romero, R., \& Yergey, A. L. (2005). Analysis of variance-principal component analysis: A soft tool for proteomic discovery. Analytica Chimica Acta, 544, 118-127.

ISO (2006). Animal and vegetable fats and oils - Determination of anisidine value. ISO standard 6885. International Organization for Standardization Geneva, Switzerland.

IOC (2001). Preparation of the fatty acid methyl esters from olive oil and olivepomace oil adopted by International Olive Council. IOC/T.20/Doc. no. 24.

Karabagias, I., Michos, C., Badeka, A., Kontakos, S., Stratis, I., \& Kontominas, M. G. (2013). Classification of Western Greek virgin olive oils according to geographical origin based on chromatographic, spectroscopic, conventional and chemometric analyses. Food Research International, 54, 1950-1958.

Kiritsakis, A., \& Dugan, L. R. (1985). Studies in photooxidation of olive oil. Journal of the American Oil Chemists' Society, 62, 892-896. 
Le Dréau, Y., Dupuy, N., Gaydou, V., Joachim, J., \& Kister, J. (2009). Study of jojoba oil aging by FTIR. Analytica Chimica Acta, 642, 163-170.

Mendez, A. I., \& Falqué, E. (2007). Effect of storage time and container type on the quality of extra-virgin olive oil. Food Control, 18, 521-529.

Morelló, J. R., Motilva, M. J., Tovar, M. J., \& Romero, M. P. (2004). Changes in commercial virgin olive oil (cv Arbequina) during storage, with special emphasis on the phenolic fraction. Food Chemistry, 85, 357-364.

Naz, S., Siddiqi, R., Sheikh, H., \& Asad Sayeed, S. (2005). Deterioration of olive, corn and soybean oils due to air, light, heat and deep-frying. Food Research International, 38, 127-134.

Pinto, R. C., Bosc, V., Noçairi, H., Barros, A. S., \& Rutledge, D. N. (2008). Using ANOVAPCA for discriminant analysis: Application to the study of mid infrared spectra of Carraghenan gels as a function of concentration and temperature. Analytica Chimica Acta, 629, 47-55.

Plard, J. (2014). Apport de la chimiométrie et des plans d'expériences pour l'évaluation de la qualité de l'huile d'olive au cours de différents processus de vieillissement [Thèse Aix-Marseille Université].
Poulli, K. I., Mousdis, G. A., \& Georgiou, C. A. (2009). Monitoring olive oil oxidation under thermal and UV stress through synchronous fluorescence spectroscopy and classical assays. Food Chemistry, 117, 499-503.

Psomiadou, E., \& Tsimidou, M. (1998). Simultaneous HPLC determination of tocopherols, carotenoids, and chlorophylls for monitoring their effect on virgin olive oil oxidation. Journal of Agricultural and Food Chemistry, 46, 5132-5138.

Pristouri, G., Badeka, A., \& Kontominas, M. G. (2010). Effect of packaging material headspace, oxygen and light transmission, temperature and storage time on quality characteristics of extra virgin olive oil. Food Control, 21, 412-418.

Shahidi, F., \& Zhong, Y. (2005). Lipid oxidation: Measurement methods. In F. Shahid (Ed.), Bailey's industrial oil and fat products (pp. 357-385). John Wiley \& Sons.

Singleton, V. L. Orthofer, R. \& Lamuela-Raventos, R. M. (1999). Analysis of tota phenols and other oxidation substrates and antioxidants by means of FolinCiocalteu reagent. Methods in Enzymology, 299, 152-178.

Sousa, A., Casal, S., Malheiro, R., Lamas, H., Bento, A., \& Pereira, J. A. (2015). Aromatized olive oils: Influence of flavouring in quality, composition, stability, antioxidants, and antiradical potential. Food Science and Technology, 60, 22-28. 